\title{
TENTANDO READQUIRIR O CONTROLE: A VIVÊNCIA DO PRÉ-ESCOLAR NO PÓS-OPERATÓRIO DE POSTECTOMIA
}

Castro AS, Silva CV, Ribeiro CA. Tentando readquirir o controle: a vivência do pré-escolar no pós-operatório de postectomia. Rev Latino-am Enfermagem 2004 setembro-outubro; 12(5):797-805.

Este estudo foi realizado com meninos de 3 a 6 anos de idade, submetidos a cirurgia de postectomia, com os objetivos de compreender o significado das interações vivenciadas por eles ante o pós-operatório de postectomia e identificar as suas estratégias enquanto vivenciam a experiência cirúrgica. O referencial teórico utilizado foi o Interacionismo Simbólico e, o metodológico, a Teoria Fundamentada nos Dados. Devido às características de desenvolvimento verbal desses meninos, a entrevista com eles foi intermediada pelo brinquedo terapêutico; suas mães também foram entrevistadas na qualidade de informantes da experiência de seus filhos. Os dados foram analisados até a fase de categorização dos significados, permitindo a emergência da categoria conceitual: Tentando Readquirir o Controle. A compreensão dessa experiência oferece subsídios importantes para o repensar a assistência de enfermagem ao menino que vivencia a postectomia e à sua família.

DESCRITORES: enfermagem pediátrica; jogos e brinquedos; fimose/cirurgia; pré-escolar

\section{TRYING TO REGAIN CONTROL: PRESCHOOL BOYS' EXPERIENCE IN THE} POST-OPERATIVE STAGE OF CIRCUMCISION

This study was carried out with 3 to 6 year-old boys undergoing circumcision, with a view to understanding the meaning of the interactions they experienced them during the post-operative period as well as identifying their strategies while experiencing the surgery. Symbolic Interactionism was used as a theoretical reference framework, and Grounded Theory as a methodological framework. Due to these children's verbal development characteristics, the interview was mediated by therapeutic play. Their mothers were also interviewed as informers of their children's experience. Data were analyzed up to the point of categorization of the meanings, revealing the following category of concepts: Trying to regain control. Understanding the whole experience offers important elements to rethink nursing care to preschool boy who undergo circumcision, as well as to his family.

DESCRIPTORS: pediatric nursing; play and toys; phimosis/surgery; child, preschool

\section{INTENTANDO READQUIRIR EL CONTROL: LA VIVENCIA DEL} PREESCOLAR EN EL POSTOPERATORIO DE POSTECTOMIA

Este estudio fue realizado con niños de 3 a 6 años de edad, que fueron sometidos a la cirugía de postectomia, con los objetivos de comprender el significado de las interacciones vividas por ellos durante el postoperatorio de postectomia e identificar sus estrategias en cuanto pasan por esta experiencia quirúrgica. El referencial teórico utilizado fue el Interacionismo Simbólico y el metodológico fue la Teoria Fundamentada en los Datos. Por las características del desarrolho verbal de esos niños, la entrevista fue intermediada por los juguetes terapeuticos. Sus madres también fueron entrevistadas como informantes de las experiencias de sus hijos. Los datos fueron analisados hasta la fase de categorización de los significados, permitiendo la emergencia de la categoria conceptual: Tentando readquirir el control. La comprensión de esta experiencia ofrece elementos importantes para el repensar de la asistencia de enfermaría a la familia y al niño que fue sometido a postectomia.

DESCRIPTORES: enfermería pediátrica; juegos y juguetes; fimosis/cirugía, preescolar

\footnotetext{
${ }^{1}$ Trabalho extraído da dissertação de mestrado apresentada a Universidade Federal de São Paulo, 2001; ${ }^{2}$ Enfermeira, Mestre em Enfermagem Pediátrica, Professor do Centro Universitário Municipal de São Caetano do Sul-IMES e do Centro Universitário Nove de Julho, e-mail: acastro@imes.edu.br; ${ }^{3}$ Enfermeira, Doutor em Enfermagem, Professor Adjunto da Universidade Federal de São Paulo
} 
INTRODUÇÃO

$\boldsymbol{U}_{\text {ma experiência cirúrgica é traumática e }}$ estressante para qualquer indivíduo, especialmente para a criança em idade pré-escolar. Seu pensamento é concreto e por isso ele reage aos objetos como esses the parecem no momento. Ele não pode nem fazer generalizações nem deduções lógicas, devido à sua incapacidade em lidar com abstrações. O pré-escolar interpreta um objeto não a partir de suas propriedades e sim em função do uso que se faz dele.

A criança com idade pré-escolar tem uma vida de fantasias ativa, pela qual interpreta os eventos externos. O perigo externo da hospitalização, da anestesia, de injeções, da perda de sangue e da intervenção cirúrgica se funde com a sua vida de fantasias interna, o que, sem uma preparação adequada, a faz experimentar tais eventos como agressões ou castigo pelo seu ciúme, sua desobediência e sua masturbação( ${ }^{(1)}$.

Visando compreender os sentimentos e reações emocionais dos meninos de três a seis anos de idade em pré-operatório de postectomia, realizamos um estudo no qual observamos a manifestação nessas crianças de sentimentos de sofrimento e tensão, ansiedade e medo; sentimentos de punição e/ou castigo; agressividade e hostilidade; medo de castração; sentimentos de negação ou desejo de fuga. Nesse contexto, a cirurgia pode ser definida como uma situação desconhecida, ameaçadora, provocadora de medo e geradora de fantasias ${ }^{(2)}$.

No entanto, ao término desse trabalho, novas indagações surgiram, entre elas: qual a interpretação que o menino faz da cirurgia, após passar da fase de abstração da experiência para a situação concreta, ou seja, a vivência da mesma? Quais as fantasias, medos e ansiedades que permeiam o período do pós-operatório? Por que alguns meninos evitam interagir com os pais e demonstram comportamentos agressivos contra eles após a cirurgia? Como o menino se percebe após ser operado? Como reage à equipe de saúde?

$\mathrm{Na}$ busca de respostas a essas questões recorremos inicialmente a ampla revisão bibliográfica e constatamos que na literatura existe uma lacuna de trabalhos recentes que descrevam a vivência do pósoperatório para a criança. Os estudos clássicos que enfocam essa temática, alguns citados a seguir, são das décadas de 40 a 80.

A cirurgia é uma experiência que traz consigo exames incômodos, contatos com sangue, mal-estar anestésico, dificuldades pós-operatórias, entre outros, e que a criança tem que enfrentar todos os sentimentos decorrentes dessa, como medo, angústias intensas relacionadas à morte, perda de partes e de separação dos pais ${ }^{(3)}$

O período pós-operatório é caracterizado por formas regressivas de comportamento, medo dos procedimentos, desconfiança, comportamento agressivo com acessos de raiva, ausência de cooperação, distúrbios de sono e alimentação, pesadelos e aumento da masturbação. Mesmo algum tempo após o retorno à sua casa, a criança pode recusar-se a permanecer sozinha à noite e requerer a presença da mãe $e^{(1)}$.

Estudo sobre os efeitos do preparo pré-operatório no comportamento das crianças antes e após a cirurgia relata que os medos fizeram com que as crianças respondessem adversamente aos eventos cirúrgicos e contribuíram para os problemas de comportamento após a hospitalização. Tais respostas incluem: pânico, agitação externa que requer restrição física, resistência ativa aos procedimentos, o esquivar-se fortemente dos cuidadores e/ou um longo período de recuperação após a cirurgia ${ }^{(4)}$. Os medos decorrentes das ansiedades e fantasias reativadas pela cirurgia tendem a persistir por períodos prolongados após a operação, de onde provém a necessidade de ajuda e orientação à criança ${ }^{(5)}$.

Para minimizar ou prevenir seqüelas e traumas cirúrgicos anteriormente abordados, é necessário estabelecer com a criança uma comunicação adequada, que the possibilite expressar seus sentimentos e pensamentos a respeito das experiências por ela vivenciadas. Uma vez que a criança em idade pré-escolar ainda não desenvolveu recursos verbais que lhe permitam exteriorizar esses sentimentos, é necessário recorrer ao brincar que é o seu meio de comunicação por excelência ${ }^{(6)}$. É por meio desse recurso que a criança lida com os seus medos, manifesta suas ansiedades, receios e apreensões, expressa sentimentos de amor e raiva, controla sua ansiedade e adquire domínio de si e do ambiente ${ }^{(2)}$.

Para compreender os sentimentos e conflitos da criança, as enfermeiras têm utilizado o brinquedo terapêutico (BT), uma atividade não-diretiva de brincar, 
cuja finalidade é permitir a ela a compreensão dos sentimentos e das reações emocionais manifestados pelas crianças, o significado que têm para elas os procedimentos intrusivos e dolorosos, assim como prepará-la para procedimentos desagradáveis, entre os quais a cirurgia ${ }^{(2,7-}$ 11).

Essas considerações impulsionaram-nos a conhecer os sentimentos e reações emocionais dramatizados pela criança que tenha vivenciado uma cirurgia genital na fase fálica, permitindo assim que os profissionais de saúde possam implementar medidas eficazes para auxiliar crianças na vivência dessa experiência. Portanto, os objetivos deste estudo são:

- compreender o significado das interações vivenciadas por meninos em idade pré-escolar no pós-operatório de postectomia;

- identificar as estratégias utilizadas pelo menino enquanto vivencia a experiência cirúrgica.

\section{FUNDAMENTAÇÃO TEÓRICO-METODOLÓGICA}

Para compreender o significado que o menino atribui à experiência de ter sido operado, optamos por realizar uma pesquisa qualitativa, pois essa tem o ambiente natural como fonte direta dos dados, o pesquisador como instrumento-chave; sendo o significado a sua preocupação essencial $^{(12)}$. Dentro das possibilidades da pesquisa qualitativa, buscamos como referencial teórico o Interacionismo Simbólico (IS) e como referencial metodológico a Teoria Fundamentada nos Dados (TFD).

O IS baseia-se em três premissas básicas: o ser humano age em relação às coisas (pessoas, objetos físicos, ações e situações) com base nos significados que elas têm para ele; os significados, objetos sociais, surgem da interação social que as pessoas estabelecem umas com as outras; os significados são manipulados e modificados por intermédio de um processo interpretativo usado pela pessoa ao lidar com as coisas que ela encontra. A cada nova situação o indivíduo definirá e redefinirá esses significados, por intermédio de um processo interpretativo, de acordo com o significado que ele atribui àquela situação $^{(13)}$.

A TFD propõe-se ao desenvolvimento de teorias geradas a partir dos dados obtidos e analisados de forma sistemática, comparativamente, num processo não-linear, durante o decorrer da própria pesquisa ${ }^{(14)}$. Enquanto o IS busca compreender o comportamento humano ao estudar as interações que os indivíduos estabelecem consigo mesmos, entre si e com os objetos, dentro de sua vida cotidiana, a TFD oferece um caminho metodológico para que os dados possam ser analisados e compreendidos.

\section{REALIZANDO A PESQUISA}

O estudo foi realizado no consultório particular de uma cirurgiã pediatra e no ambulatório de cirurgia pediátrica de um hospital público infantil, ambos localizados no município de São Paulo. Participaram do mesmo 12 meninos pré-escolares, na faixa etária de 3 a 6 anos de idade, dos quais quatro foram entrevistados no consultório particular e oito no ambulatório do hospital público. Esse número foi determinado pelo resultado do processo de amostragem teórica, conforme preconizado na TFD.

Antes do seu início, o projeto foi avaliado e aprovado pela Comissão de Ética da Universidade Federal de São Paulo e autorizado pelas instituições nas quais ocorreria a coleta de dados, e os pais das crianças participantes assinaram o termo de esclarecimento livre e esclarecido.

A coleta dos dados ocorreu de abril a agosto de 2000, no sétimo dia de pós-operatório, quando é agendada a consulta de retorno da cirurgia. Para fazer a seleção dos meninos era consultado semanalmente o livro de registro do centro cirúrgico do hospital infantil e mantinhase contato telefônico, também semanal, com a cirurgiã ou a recepcionista de seu consultório. As estratégias adotadas para a coleta de dados foram a entrevista com o menino, intermediada pelo brinquedo terapêutico, e entrevista com a mãe, na qualidade de informante da experiência da criança.

A entrevista com o menino foi realizada por meio de uma sessão individual de brinquedo terapêutico, que era realizada em uma das salas disponíveis do consultório particular, ou do ambulatório do hospital infantil. A mãe e/ ou o pai permaneciam próximos ao menino durante a brincadeira, a fim de que ele se sentisse protegido e seguro, já que estava nos conhecendo naquele momento. Os pais eram anteriormente orientados a não identificar 
os brinquedos e a devolver a pergunta ao menino, quando questionados sobre algo, para que todas as decisões a respeito da brincadeira fossem tomadas por ele.

Cerca de 15 minutos após o início da sessão, com o intuito de focalizar o tema da brincadeira para a sua cirurgia, e assim obter dados sobre os sentimentos e sobre o significado que o menino atribui a essa experiência, fazíamos a seguinte pergunta orientadora: "Vamos brincar de um menino que foi operado?".

Esse convite costumava desencadear uma série de verbalizações, as quais foram gravadas, e dramatizações do menino, a partir das quais íamos formulando perguntas e fazendo reflexões para que ele continuasse a brincar e para que pudéssemos compreender melhor a situação imaginária dramatizada por ele na brincadeira. Porém, em nenhum momento tentamos refletir sobre seu comportamento não-verbal ou sugerir que o menino estivesse falando de si mesmo; participamos, muitas vezes, da sua brincadeira, para auxiliá-lo a manusear os materiais hospitalares quando éramos solicitadas, bem como para realizarmos uma atividade determinada por ele, conforme preconiza os princípios da técnica ${ }^{(10)}$.

A entrevista com a mãe foi realizada com o intuito de esclarecer a compreensão dos comportamentos verbais e não-verbais manifestados pelo menino durante a brincadeira, bem como para saber como seu filho se comportara desde o momento em que fora agendada a cirurgia até o momento em que ele retorna para a consulta de pós-operatório.

Essas entrevistas ocorreram logo após o término da sessão de brinquedo terapêutico e tiveram duração de 15 a 30 minutos, tendo sido gravadas com autorização prévia e posteriormente transcritas na íntegra. Houve duas entrevistas nas quais o entrevistado foi o pai, por ser ele quem acompanhava o menino, e uma na qual entrevistamos o casal.

A entrevista foi do tipo semi-estruturada, e para iniciá-la utilizamos a seguinte pergunta aberta: "Conteme sobre as reações do seu filho desde o dia em que ele foi informado de que seria operado até hoje que ele está retornando para consulta".

Após transcrever as entrevistas dos meninos e das mães, os dados foram analisados, seguindo os passos preconizados pela TFD ${ }^{(15-16)}$ que são: codificação aberta, que consiste em identificar e analisar os dados e conceituá-los em forma de códigos; categorização, processo de agrupar os códigos por similaridades e diferenças, formando categorias; e a codificação teórica, que consiste no processo de especificar as categorias a um fenômeno a partir de aspectos que dela sobressaem. Apesar dessa metodologia propor-se à elaboração de um modelo teórico, este estudo teve como objetivo descrever as categorias de significados para compreender a experiência do menino operado de fimose. Por ser uma metodologia que se configura em um processo de contínua construção, foi possível interromper a pesquisa nesta etapa sem incorrer em um erro metodológico.

\section{CONTANDO A EXPERIÊNCIA VIVENCIADA PELO PRÉ-ESCOLAR}

A experiência do menino no pós-operatório de postectomia revelou-se na categoria conceitual, Tentando Readquirir o Controle (Figura 1), a qual descreve as ações, reações e sentimentos experienciados pelo menino a partir do momento em que ele sai da sala operatória e, acordando, passa a se defrontar com repercussões do trauma cirúrgico.

Ter vivenciado o procedimento cirúrgico desencadeia no menino algumas reações. Num primeiro momento, embora sentindo-se aliviado por já ter sido operado, o menino defronta-se com sensações desagradáveis, representadas principalmente pela dor e o desconforto do pós-operatório, além de sentir-se agredido e enganado ao perceber que nem tudo o que lhe foi dito se comprova. Tudo isso faz com que o menino fique amedrontado e magoado. Apesar disso, ele revela sua força, tentando readquirir o controle no sentido de ter uma vida normal de criança. Nesse contexto, ele busca e recebe o apoio e a proteção da mãe.

A categoria, por conseguinte, é composta pelas seguintes subcategorias: Passando pela cirurgia; Sentindose amedrontado; Ficando magoado; Buscando a proteção da mãe; Sendo apoiado e protegido pela mãe; Não querendo relembrar; Tentando se defender; Tentando entender; Não aceitando as restrições; Mostrando que já é grande; Reafirmando que é homem; Querendo ficar bom, que descrevem o significado dessa vivencia para o menino pré-escolar. 


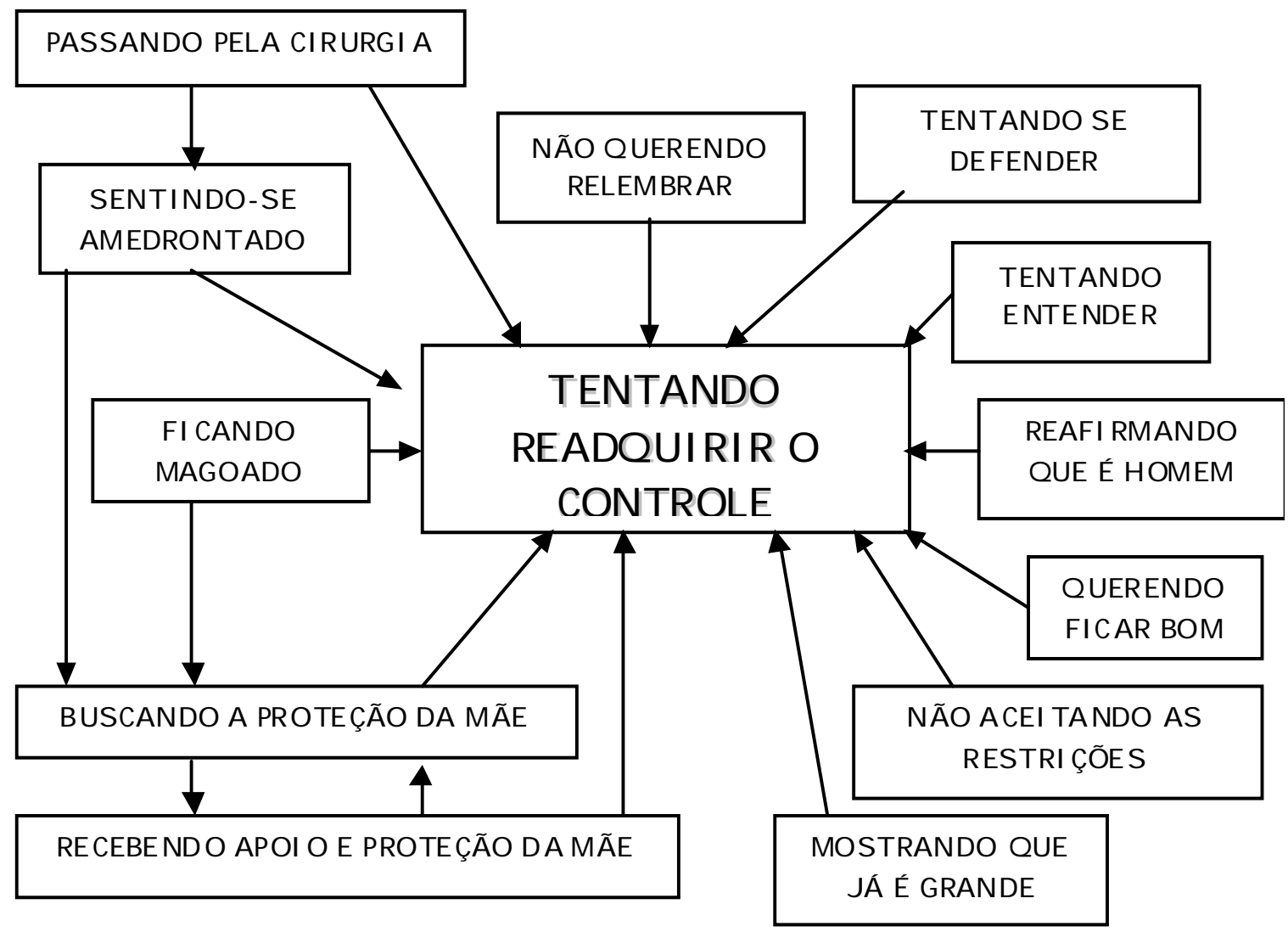

Figura 1 - Categoria Conceitual - tentando readquirir o controle

Passando pela cirurgia

A vivência do pós-operatório imediato tem início com o término do evento cirúrgico propriamente dito e é influenciada pela interpretação que o menino faz da operação, desde o momento em que, antes da cirurgia, passa a se defrontar com alterações em sua rotina e no comportamento de seus pais, que indicam para ele que algo diferente está acontecendo. Essa vivência é marcada por repercussões físicas como dor e desconforto, restrições e mudanças corporais e repercussões emocionais, das quais emergem sentimentos e reações que impulsionam o menino a enfrentar a nova realidade.

Sentindo-se aliviado é como o menino se sente após o término angustiante e amedrontador do préoperatório, período caracterizado pela vivência de um grande suspense, durante o qual ele sentiu medos, ansiedades e apreensões. Ter passado pela cirurgia é um alívio, é como se ele acordasse de um terrível pesadelo.

Mãe: Ele falou para mim: só que agora eu tô calmo, quer dizer que ele tava nervoso mesmo, é que ele não quis falar.... (Entrevista com a Mãe-EM).

Tendo medo de morrer é um sentimento relatado e dramatizado pelos meninos durante as sessões de brinquedo terapêutico, nas quais, após dramatizarem um ato cirúrgico, cortando um segmento do corpo de um boneco ou animal, preocupam-se em enfaixar muito bem o local, com uma "faixa comprida" para evitar que "o bicho morra".

Menino: Quem é o próximo? Enfaixa o rabo do bicho, quer que o bicho morra?, pegando o gato (BT).

Durante a sessão de brinquedo terapêutico os meninos demonstram o quanto estavam se sentindo agredidos pelo procedimento cirúrgico propriamente dito ao dramatizarem e verbalizarem que operar é beliscar e apanhar, e quando manuseiam o revólver após serem convidados para brincar de um menino que foi operado. $\mathrm{O}$ menino também se sente agredido pelos objetos que são utilizados nos procedimentos aos quais normalmente é submetido quando operado, principalmente pela injeção, que foi amplamente dramatizado durante a sua brincadeira. Ele também se sente agredido pelas pessoas do hospital e vê no médico um agressor e, na enfermeira, uma aliada do médico, que o agridem realizando procedimentos dolorosos e amedrontadores.

Menino: Brincar de médico a gente espeta, pega a boneca e a seringa com agulha e dá injeção no braço (BT).

Sentindo-se enganado, é como o menino se sente 
quando percebe que o que ele está vivenciando no pósoperatório não corresponde ao que lhe foi dito anteriormente a respeito da operação, especialmente sobre o que iria sentir depois dela. Ele demonstra isso verbalizando que mentiram para ele a respeito de que não sentiria dor e que seu pênis ficou feio e não mais bonito como the haviam garantido.

Mãe: ... aí ele falou assim: você mentiu pra mim, eu falei: por quê? Ele falou: tá doendo, você falou que não ia doer, eu falei: ahhh, tá doendo aonde? Aí ele falou que tava doendo o pinto dele... (EM).

Mãe: ... ele só no começo ele falava assim por que que eu fui colocar esse anel? Que ela colocou o anelzinho, que era tão bonitinho, agora tá feio, eu não quero mais ficar com o pipi igual o do meu pai (EM).

Sentindo-se amedrontado

O menino, por se sentir agredido pelo procedimento cirúrgico e enganado por seus pais, e pelo fato de sentir dor e desconforto, vivencia o período pósoperatório sentindo-se amedrontado. Este período é caracterizado por muito medo, principalmente de sentir dor e de ser novamente punido. Neste sentido, ele passa a se alimentar melhor, aceitando e pedindo alimentos que antes não apreciava, como também mostra-se mais obediente e procura não contrariar os pais.

Mãe: ... então ele não era de comer... então, eu tô achando muito bom pela alimentação dele... ele vai lá, pega a maçã, a banana, descasca e come... isso tudo depois da operação, porque eu perguntei se podia comer de tudo, ela falou que podia... café com leite, L. nunca gostou, L. agora pede... entendeu... farinha láctea, ele detestava, eu faço farinha láctea, faço mucilon e faço cremogema... ele toma tudo.... (EM).

O sentimento de medo aumenta quando ele retorna ao consultório do cirurgião pediatra, lugar onde percebeu que algo diferente iria lhe acontecer, ou ao hospital pela possibilidade de que algo novamente the aconteça, nesse local onde anteriormente sentiu-se agredido.

Mãe: ... hoje quando eu falei que ele ia vir no hospital de novo, ele falou: mãe, não vai mexer no meu pinto de novo não, né... (EM).

Ao se sentir ameaçado pelo ambiente ou objeto, o menino mantém sua atenção voltada para ele e a tudo o que está acontecendo ao seu redor, a ponto de não se sentir com liberdade e segurança para brincar.
Ficando magoado

A dor, o medo de sentir dor, as restrições, a convivência com as mudanças do corpo, o fato de sentirse enganado pelos pais, de sentir-se agredido e de estar tão amedrontado determinam que o menino sinta-se magoado com toda a situação, especialmente com seus pais. Uma das formas que o menino encontra para expressar essa mágoa é comportando-se agressivamente, inclusive contra a sua mãe, seja na realidade ou simbolicamente na brincadeira.

Mãe: Nervoso, ele ficou bastante nervoso... Tipo assim, roupa... ele não queria colocar, ele ficava nervoso. Ele dá capoeira, né... aí ele ficava assim chutando a gente, os brinquedos ele não queria saber... (EM).

Menino: Vou pegá o revólver; pega o revólver que estava no chão; movimenta-se pelo lençol com o revólver na mão dizendo: Revólver; levanta-se e vai para a parede, me mostra o revólver dizendo: Olha, com o dedo no gatilho. Eu: O que você vai fazer? Menino: Fazê? Eu: É. Menino: Atirar. Eu: Em quem você vai atirar? Menino: Aponta o revólver indicando para a mãe. Eu: Na mãe? (BT).

Buscando a proteção da mãe

Embora sentindo-se magoado, especialmente com a mãe, é a ela que o menino recorre quando se sente fragilizado e amedrontado. Para conseguir defender-se, não só física mas principalmente emocionalmente, o menino mostra-se dependente da mãe, que representa para ele fonte de apoio e segurança, ou seja, o porto seguro em que ele encontrará o abrigo acalentador para se proteger e adquirir forças para enfrentar seus medos e assumir novamente o controle da situação. Buscando proteção da mãe, o menino utilizará formas de comportamento próprias de crianças menores ou apresentará novas formas de agir e se comportar, seja refugiando-se na mãe, ou não querendo separar-se dela.

Mãe: ... o que eu faço com meu bebê que tem seis meses, ele também queria. Queria mamar, se eu desse mama deitadinho como ele tá... Então ele teve reações umas assim, nesse sentido, coisa que ele não tinha... (EM).

Mãe: ... não sei se foi devido à cirurgia que ele ficou mais teimoso, mais sensível, né, querendo mais colo, querendo mais a minha presença. Qualquer lugar assim, se eu vou numa padaria, por exemplo, ele começa a chorar... ele não fazia isso, chorar me chamando, queria sempre a minha presença, no colo também, bastante, também não tinha isso.... (EM). 
Ao perceber as solicitações de proteção e apoio expressados pelo filho, a mãe se mobiliza no sentido de protegê-lo e apoiá-lo após o procedimento cirúrgico. O menino, portanto, passa a receber da mãe mais atenção, explicações sobre a cirurgia e sobre as restrições.

Mãe: ... apesar de que eu tirei um feriado prolongado pra gente... a gente fazer a cirurgia. Então eu fiquei todo o tempo do lado dele, né... todo mundo paparicando... (EM).

Mãe: Aí ele perguntou, ele tava tomando banho e ele perguntou por que... por que o médico corta?... e eu falei... só que o médico tinha cortado um pouquinho para aparecer melhor (EM).

Não querendo relembrar

É um mecanismo utilizado pelo menino para se resguardar de todo o sofrimento vivido no pré- e principalmente agora no pós-operatório. Assim, quando questionado sobre a sua cirurgia, muitas vezes ele evita falar, muda o rumo da conversa ou nada fala. Também, durante a sessão de brinquedo terapêutico, ao ser convidado para brincar de um menino que foi operado, ele imediatamente interrompe a brincadeira ou diz que não sabe brincar.

Mãe: ... a gente pergunta como foi a operação, ele fala: eu não sei, ou senão ele fala: eu não quero falar sobre isso, ele já muda de assunto... (EM).

Eu: $R$., eu tive uma idéia, vamos brincar de um menino que foi operado? Menino: Fica estático em frente da sacola, sem me olhar... Mas eu não sei. Eu: Como você acha que brinca? Menino: Também não sei... senta-se em frente da sacola; vira-se para a porta; sentado olha para as paredes; está quieto e assim permanece por alguns minutos. Eu: Você não quer mais brincar? Menino: Eu quero ir embora $(B T)$.

Tentando se defender

Durante as sessões de brinquedo terapêutico, o menino utilizava o revólver como instrumento de defesa, apontando e atirando para as pessoas que entravam na sala, para os bonecos médicos e enfermeira e também para os objetos hospitalares. Além disso, o menino chuta, joga e destrói os materiais hospitalares: ele corta ou rasga esses objetos, mesmo que para isso precise do meu auxílio. sacola manuseando o celular. Auxiliar de enfermagem: Abre a porta por engano. Menino: Vira-se em direção à porta; fecha o celular, coloca ao lado do carro; mexe na sacola; pega o revólver, manuseiao, coloca o dedo no gatilho, porém não dispara e após guarda na sacola $(B T)$.

Tentando entender

No pós-operatório o menino procura encontrar uma explicação do porquê teve que ser operado, por vezes repetindo o que the foi falado (fimose) ou o que ouve a respeito das pessoas doentes no seu convívio familiar.

Pai: ... só que ele perguntava muito né... Eu: Perguntava o quê? Pai: Da fimosa, como ele chama. Eu: E o que ele queria saber da fimose? Pai: Ele queria, aaahhh, todo mundo que pergunta: $C$. veio de onde?. Ah, venho da cirurgia da fimosa, ele sempre fala... (EM).

Não aceitando as restrições

Da mesma forma que o menino, por se sentir bem e não entender porquê foi operado, ele também não entende porquê precisa ter restrições da atividade física. Assim, em mais uma tentativa de assumir o controle de sua vida ele reclama e se rebela contra tais restrições e sempre que tem oportunidade ele pula, corre e brinca livremente, mesmo que tais atividades provoquem dor.

Mãe: ... só que ele fica bonzinho quando eu tô em casa, porque eu trabalho, então ele fica com a minha mãe. Então, ele aproveita o tempo que passa com a minha mãe, se enfia embaixo da cama, enfia embaixo da mesa e correr... (EM).

Mostrando que já é grande

Tentando superar a percepção de sentir-se pequeno e assim ter de submeter-se à cirurgia, o menino demonstra e verbaliza durante a brincadeira que não é mais nenê ou criança pequena e, portanto, não usa mais chupeta ou mamadeira pequena. Sendo assim, ele não tem mais de se submeter à vontade dos adultos que the impuseram a cirurgia.

Menino: ... mexe na sacola, tira a mamadeira pequena perguntando: Que é isso?; Eu: O que você acha que é? Menino: Manuseia, retira a tampa e diz: Mamadeira. Eu: Mamadeira? Menino: De nenê e coloca-a no chão sem a tampa (BT). 
Reafirmando que é homem

Após a cirurgia, o menino demonstra ter grande preocupação com relação à integridade e funcionalidade de seu pênis. Ele olha e o exibe constantemente, para mostrar a si mesmo e aos outros que seu pênis não foi cortado, como ele temia no pré-operatório. Embora o medo da mutilação esteja presente em todas as faixas etárias, esse temor é especialmente vivenciado pelo pré-escolar que, devido às características de seu desenvolvimento, se preocupa muito com os órgãos genitais.

Mãe: Toda hora que o pintinho dele tá duro, ele tem que mostrar pra alguém, pode ser quem for. Qualquer pessoa que chega em casa ele: ó meu pinto ó... já mostra, pode ir, toda hora que tá duro ele já ó: ficou duro, ó, vem ver ... é desse jeitinho... tudo agora pra ele é o pinto (EM).

\section{Querendo ficar bom}

É o que o menino demonstra ao perguntar insistentemente para a mãe se o local operado já não está bom ou quando questiona quantos dias faltam para cair o anel de borracha. Ele parece ansioso para sarar e, assim, pôr fim à continuidade do seu desconforto, suas restrições e seus temores e, desse modo, poder brincar e levar uma vida própria de sua idade.

Mãe: ... até hoje, agora ele olha, né... aí ele fica toda hora: mãe, já não tá bom? Quero andar de bicicleta, mãe, olha, já não gruda mais... (EM).

\section{REFLETINDO SOBRE A VIVÊNCIA DESVELADA}

Permitir que o menino pré-escolar operado de fimose contasse a sua experiência nos possibilitou compreender que essa vivência se configura numa história de muito medo, medo que não cessa quando termina a operação, permeando todas as etapas do processo cirúrgico. Analisando esses achados a partir do referencial teórico utilizado, o IS, pudemos verificar que o significado que o menino dessa idade atribui a essa vivência está intrinsecamente relacionado à interação que ele estabelece com o seu corpo, com a sua família, principalmente a mãe, e com as etapas que compõem todo o procedimento cirúrgico.

Antes de interagirmos com os dados, não imaginaríamos que no período pós-operatório o menino continuasse a ter o medo de ficar sem o pênis, porém foi esse temor que se manifestou quando ele ficava observando e exibindo seu pênis, principalmente para mostrar a si mesmo que ele não havia sido cortado.

Alguns meninos acreditam que após uma cirurgia de fimose, o seu pênis não esteja mais intacto e que possivelmente tenham mudado de sexo, como o relato do caso de um menino de cinco anos que, após ser operado, ficava levantando a camisola para mostrar seus órgãos genitais às pessoas que passavam pelo quarto e que, em uma ocasião, foi encontrado vestido com trajes de menina $^{(17)}$.

Esses dados impulsionam-nos a corroborar com os autores desse trabalho de que se deva considerar a etapa de desenvolvimento emocional do menino antes de se realizar uma cirurgia quando não há qualquer mal aparente, principalmente uma cirurgia genital, numa fase em que essa região do corpo é carregada de simbolismos. Ressaltamos ainda a importância de esclarecer e apoiar os pais para que eles possam tranqüilizar-se e ajudar positivamente o filho nessa vivência.

O relacionamento que a mãe mantém com a criança é de tal nível que pode ser comparado àquele exercido pelo terapeuta sobre seu cliente, uma vez que permeado de calor, de compreensão e sendo visto como um porto de referência no qual a criança busca apoio quando se vê obrigada a enfrentar situações difíceis e amedrontadoras. Para que as mães exerçam essa função terapêutica, há a necessidade de que também elas sejam atendidas e cuidadas, pois durante as situações que implicam doença e hospitalização elas têm de lidar não apenas com o sofrimento da criança, mas também com o seu próprio sofrimento ${ }^{(18)}$.

Assim como no trabalho acima, os dados deste estudo reforçam a importância de se repensar o enfoque da assistência de enfermagem centrada na família, em especial na assistência à criança, que é particularmente dependente de efetivas interações com os pais para crescer e se desenvolver.

Finalizando, gostaríamos de comentar que, embora muitas das reações à cirurgia aqui descritas já tenham sido comentadas em outros trabalhos, como aqueles abordados na introdução deste estudo, ouvir o menino permitiu-nos a compreensão do significado da vivência da postectomia para ele, aprofundando relevantes aspectos dessa vivência e revelando novos enfoques.

Ressaltamos que a vivência desvelada oferece subsídios importantes para repensar a assistência ao 
menino que vivencia a postectomia, especialmente em relação à escolha de uma idade para a sua realização em que ele possa compreender melhor os motivos da cirurgia, a importância de prepará-lo, respeitando seu foco de

\section{REFERÊNCIAS BIBLIOGRÁFICAS}

1. Legrand DD. Psychoanalytic principles applied to pediatric surgery. Md State Med J 1964 Mar; 13(3):113-7.

2. Castro AS, Ribeiro, CA, Silva CV. Sentimentos e reações emocionais manifestados por crianças de 3 a 6 anos de idade, no pré-operatório imediato de postectomia, durante uma sessão de brinquedo terapêutico. Acta Paul Enfermagem 2000; 13(especial Pt 2):182-5.

3. Trinca AMT. A cirurgia do pequeno Hans como fator de intensificação de sua fobia. Rev Bras Pesqui Psicol 1991; 1(3):71-4.

4. Schmidt CK. Pre-operative preparation: effects on immediate pre-operative behavior, post-operative behavior and recovery in children having same-day surgery. MaternalChild Nurs J 1990; 19(4):321-30.

5. Moore WT. The impact of surgery on boys. In: Moore WT. The psychoanalytic study of the child. New Haven: Yale University Press; 1975. p. 529-48.

6. Geets C. Melanie Klein. São Paulo (SP): EDUSP; 1977. p. 17-40.

7. Martins, MR. O efeito do brinquedo terapêutico sobre o comportamento da criança submetida à cirurgia eletiva. [tese]. São Paulo (SP): Universidade Federal de São Paulo/ UNIFESP; 2001.

8. Neira Huerta EPN. Preparo da criança e família para procedimentos cirúrgicos: Intervenção de enfermagem. Rev Esc Enfermagem USP 1996 Ago; 30(2):340-53.

9. Ribeiro CA, Borba RIH, Sabatés AL, Maia EBS, Almeida FA, Rezende, MA. $O$ brinquedo e a assistência de enfermagem à criança. Enfermagem Atual 2002 Nov/dez; (24):6-17.

10. Brêtas JRS, Santos FQ, Castro AS, Genovese RE, Martins MR, Manásia LAH, et al. Contribuições para o cuidado emocional à criança hospitalizada. Acta Paul Enfermagem 2002 out/dez; 15(4): 87-95.

11. Martins MR, Ribeiro CA, Borba RIH, Silva CV. Protocolo de preparo da criança pré-escolar para punção venosa, com utilização de brinquedo terapêutico. Rev Latino-am Enfermagem 2001 março; 9(2):76-85.

12. Triviños ANS. Introdução à pesquisa em ciências sociais: a pesquisa qualitativa em educação. São Paulo (SP): Atlas; 1990.

13. Blumer H. Symbolic interacionism: perspective and method. Califórnia: Prentice Hall; 1969.

14. Angelo M. Vivendo uma prova de fogo: as experiências iniciais da aluna de enfermagem. [tese]. São Paulo (SP): Escola de Enfermagem/USP; 1989.

15. Strauss AL, Corbin J. Basics of qualitative research: grounded theory procedures and tecniques. California: Sage; 1991.

16. Glaser BG. Theorical sensivity. Mill Valley: Sociology Press; 1978.

17. Petrillo M, Sanger S. Cuidado emocional del niño hospitalizado. México: Prensa Médica: 1972. p. 111-49. preocupação e seu estágio de desenvolvimento, assim como a importância de esclarecer e apoiar os pais para que eles possam se tranqüilizar, auxiliar e apoiar seus filhos.
18. Ribeiro CA. Crescendo com a presença protetora da mãe: a criança enfrentando o mistério e o terror da hospitalização. [tese]. São Paulo (SP): Escola de Enfermagem/USP; 1999. 